\title{
A New Handheld Air Impulse Tonometer
}

\author{
J H FISHER ${ }^{1}$, P G WATSON ${ }^{2}$ and G SPAETH ${ }^{3}$
}

Royston, Cambridge and Philadelphia

\begin{abstract}
Summary
A new type of non-contact tonometer is described. The instrument is handheld and incorporates a system which automatically generates the measuring pulse of air when the alignment is correct. A brief description of the design and the results of clinical trials are presented. These establish a good correlation with paired Goldmann readings (correlation coefficient, $r=0.88$ to 0.95, standard deviation, S.D. 1.56 to $2.66 \mathrm{~mm} \mathrm{Hg}$ ).
\end{abstract}

\section{Background}

It is now some 14 years since the introduction of the first commercial non-contact air impulse tonometer (NCT). ${ }^{1}$ During this period there have been many clinical trials which have established the correlation of the readings of the NCT with those of the conventional Goldmann instrument, and a summary of the most significant results is shown in Table I.

Apart from one paper ${ }^{5}$ which questions the accuracy at very high intra-ocular pressures (IOPs), the results have established the NCT as a valid and useful instrument.

\section{Design of the New air Impulse Tonometer}

The Pulsair tonometer shown in Figs 1 and $2^{9}$ has been designed with a handpiece which can be taken to the patient's eye. This can often provide a major advantage over instruments which require the use of a head and chin rest to locate the patient's head. Thus the instrument is easy to use with the patient in any position - a particular advantage with infirm or very young patients. In addition, it is possible to use it on young infants and older children who will not keep their eyes sufficiently still for a contact measurement.

The instrument applies a ramped air impulse to the eye, and gauges the intra-ocular pressure from a measurement of pressure in the air delivery system at the applanation event ${ }^{9}$. Two levels of air impulse are provided allowing IOPs of up to $33 \mathrm{mmHg}$ to be tested with a much reduced peak and volume of air.

The corneal monitoring system incorporates a series of lenses, combined with the reflecting surface of the cornea, to form two images of a test object. One of these is viewable by the operator, whilst the other is formed onto an array of photodetectors. The detectors measure the image contrast to determine when the image is in focus, and thus when the instrument is correctly aligned and spaced from the eye. When this condition is satisfied the air impulse is automatically initiated.

As the air pressure on the cornea exceeds the IOP the cornea distorts, the optical system detects this event, and the pressure is instantaneously sampled using the pressure transducer (Fig 2).

\section{Calibration of the Pulsair Tonometer}

Initial development of the instrument was carried out on Pigs' eyes. Then, beginning in 1985 a series of clinical trials was undertaken

1. J H Fisher M. Phil. Technical Director PA Technology Cambridge Laboratory, Melbourn, Royston, Herts SG8 6DP

2. P G Watson F.R.C.S. Consultant Ophthalmologist, Addenbrookes Hospital, Hills Road, Cambridge

3. G Spaeth M.D. Wills Eye Hospital, 9th and Walnut Street, Philadelphia PA 19107, U.S.A. 
Table I Key published results comparing the AO NCT with the Goldmann

\begin{tabular}{|c|c|c|c|c|c|}
\hline & No of eyes & $\begin{array}{l}\text { Corr } \\
\text { coeff }\end{array}$ & $\begin{array}{c}\text { SD of } \\
\text { differences }\end{array}$ & Slope & Intercept \\
\hline Forbes $^{(2)}$ & 570 & 0.90 & 2.86 & 0.95 & 1.01 \\
\hline Halberg ${ }^{(3)}$ & 267 & 0.86 & 3.17 & 1.02 & 1.20 \\
\hline Decker \& Keuther ${ }^{(4)}$ & 94 & 0.96 & 2.38 & 0.85 & 3.34 \\
\hline Draeger et $_{\text {al }}{ }^{(5)}$ & $80+$ & 0.87 & 2.16 & 0.94 & 0.49 \\
\hline Dittmar et al ${ }^{(6)}$ & $64+.+$ & 0.72 & 6.56 & 1.09 & -2.02 \\
\hline Kitazawa et al(7) & 229 & & 3.99 & 1.03 & -1.53 \\
\hline \multirow[t]{3}{*}{ Shields ${ }^{(8)}$} & 271 & 0.94 & 2.14 & 0.94 & .03 \\
\hline & $593^{*}$ & 0.84 & 2.57 & 0.7 & 0.46 \\
\hline & $47^{* *}$ & 0.95 & 3.3 & 1.16 & -0.88 \\
\hline
\end{tabular}

$+<23 \mathrm{mmHg} *<27 \mathrm{mmHg}$

$++>23 \mathrm{mmHg}^{* *}>27 \mathrm{mmHg}$

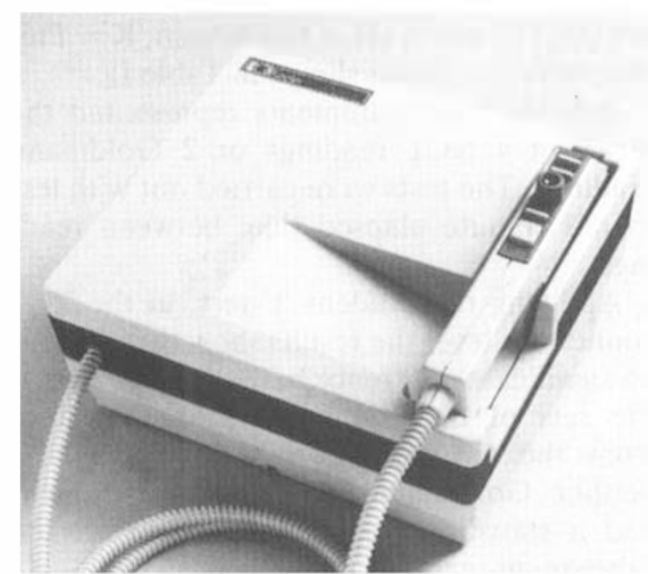

Fig. 1. The Pulsair Tonometer

to establish the calibration of the Pulsair instrument to the Goldmann. These trials have been carried in the glaucoma clinics of Hinchingbrooke Hospital, Huntingdon UK, Addenbrookes Hospital, Cambridge UK and at the Wills Eye Hospital, Philadelphia USA.

A good protocol for the standardisation of tonometers is that recommended by Jessen. ${ }^{10}$ This involved three operators, two Goldmann instruments $(G)$ and the new tonometer $(\mathrm{T})$.

Three measurements are taken and averaged for each instrument according to an action plan in which the operators and order of use of the instruments is changed at random. Regression is then carried out between the mean of 3 readings of $T$ and the 6 readings of $\mathrm{G}$.

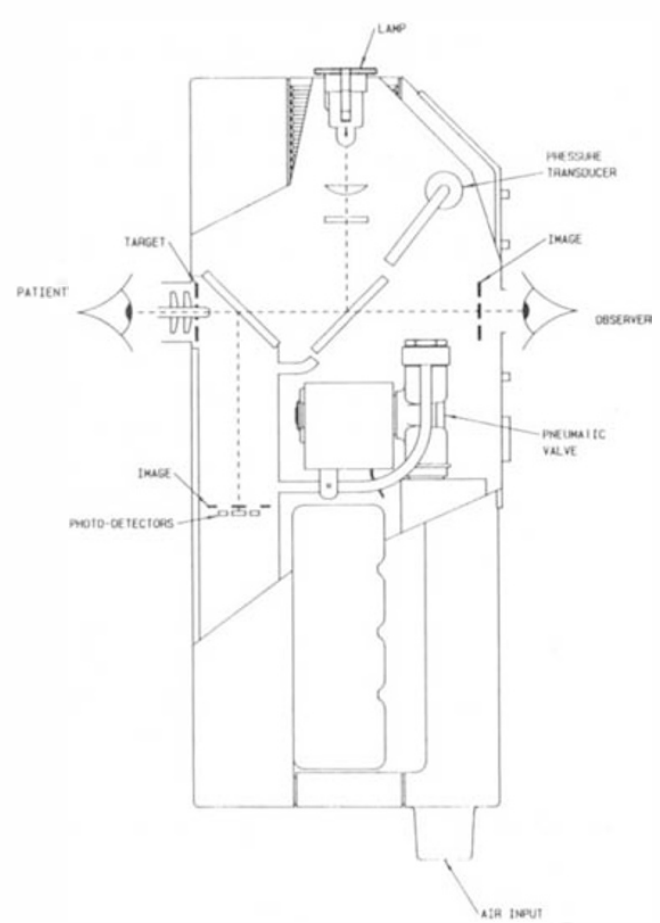

Fig. 2. Principle components of the Pulsair handpiece

In practice, however, to minimise patient discomfort and the interference with the clinic, we adopted slightly modified procedures.

For example that used in the UK was as follows.

Operator $A$ took 4 readings on each eye using the Pulsair. 
Operator $B$ took 2 readings on each eye using Goldmann G1.

Operator $C$ took 2 readings on each eye using Goldmann G2.

For the US results.

Operator $A$ took 4 readings on each eye using the Pulsair

Operator $A$ then took 2 'blind' Goldmann readings with operator $\mathrm{B}$ noting the reading and re-setting the tonometer to zero each time.

Operator $B$ then repeated the 'blind' Goldmann readings using operator $A$ in the same way as operator B did in the previous test.

Operators A and B were orthoptists or technicians particularly experienced in conventional tonometry, and operator $\mathrm{C}$ was the patient's clinic doctor.

The time between A and B was typically a few minutes, however the time between $B$ and $C$ could vary from about 1 minute to more than 30 minutes depending on how

Table II Effects of changing sequence in clinical trials

\begin{tabular}{ccccc}
\hline Test & & Sequence & $\begin{array}{c}\text { Change between } \\
\text { means of } \\
\text { Goldmann } \\
\text { readings }\end{array}$ \\
\hline 1 & $\mathrm{G}_{1 \mathrm{~A}}$ & $\mathrm{~K}_{\mathrm{C}}$ & $\mathrm{G}_{2 \mathrm{~A}}$ & $-0.8 \mathrm{mmHg}$ \\
2 & $\mathrm{G}_{1 \mathrm{~A}}$ & $\mathrm{~K}_{\mathrm{C}}$ & $\mathrm{G}_{2 \mathrm{~B}}$ & $-0.4 \mathrm{mmHg}$ \\
3 & $\mathrm{~K}_{\mathrm{C}}$ & $\mathrm{G}_{1 \mathrm{~A}}$ & $\mathrm{G}_{2 \mathrm{~B}}$ & $-0.17 \mathrm{mmHg}$ \\
4 & $\mathrm{G}_{1 \mathrm{~B}}$ & $\mathrm{G}_{2 \mathrm{~A}}$ & $\mathrm{~K}_{\mathrm{C}}$ & $+1.2 \mathrm{mmHg}$ \\
\hline
\end{tabular}

quickly the patients were seen subsequently in the clinic.

The two Goldmann tonometers used in each case were regularly calibrated.

The main difference between our basic protocol and that of Jessen is that it does not take account of any effect which the measurement may have on the subsequent IOP. This possible effect was therefore evaluated via a separate trial.

\section{Results}

Investigation of the effect of measurements on subsequent IOP

One-hundred and twenty normal eyes were tested using operators A, B and C (orthoptists or technician in this case) and tonometers $\mathrm{G} 1, \mathrm{G} 2$ and $\mathrm{K}$ ( $\mathrm{G}=$ Goldmann, $\mathrm{K}=$ Pulsair) with the results shown in Table II.

Individual measurements represented the mean of 4 NCT readings or 2 Goldmann readings. The tests were carried out with less than 1 minute elapsed time between readings.

Applying the Student ' $t$ ' test, at the $95 \%$ confidence level the results show that there is no significant difference between the mean of the sets of individual Goldmann readings from the two operators A and B. Also neither Goldmann nor Pulsair instrument had a statistically significant effect on the subsequent readings.

\section{Clinical Trials}

The main clinical tests were carried out in 7 main sets involving different tonometers and

Table III Results of clinical trials for the Pulsair vs paired Goldmann readings

\begin{tabular}{lrrrrr}
\hline Test date & $n$ & $r$ & $S D$ & slope & intercept \\
\hline Nov 1985 & 86 & 0.91 & 2.51 & 0.93 & 3.6 \\
Feb 1986 & 112 & 0.88 & 2.40 & 0.79 & 5.46 \\
Feb 1986 & 98 & 0.89 & 2.66 & 0.78 & 4.47 \\
Apr 1986 & 119 & 0.91 & 2.23 & 0.90 & 4.77 \\
Nov 1986 & 175 & 0.91 & 2.23 & 0.73 & 3.67 \\
Dec 1986 & 108 & 0.92 & 1.56 & 0.54 & 2.79 \\
Feb 1987 & 75 & 0.95 & 2.36 & 0.95 & 0 \\
& & & & & \\
\end{tabular}

The results in 1985, 1986 were used as the basis of calibrating the instruments for 1987. 


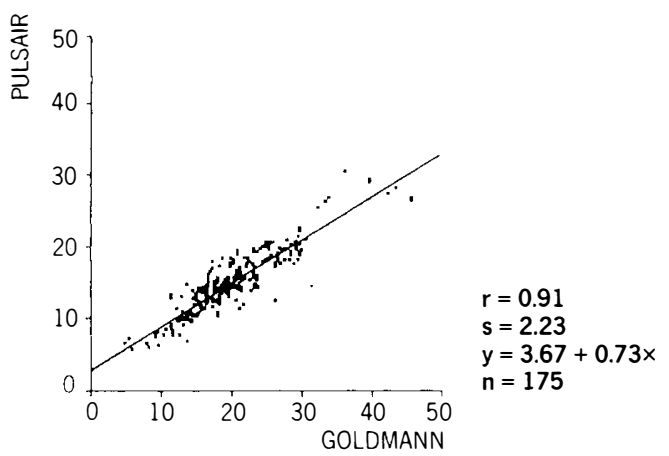

Fig. 3. Example of a scatter diagram from clinical trials before final calibration

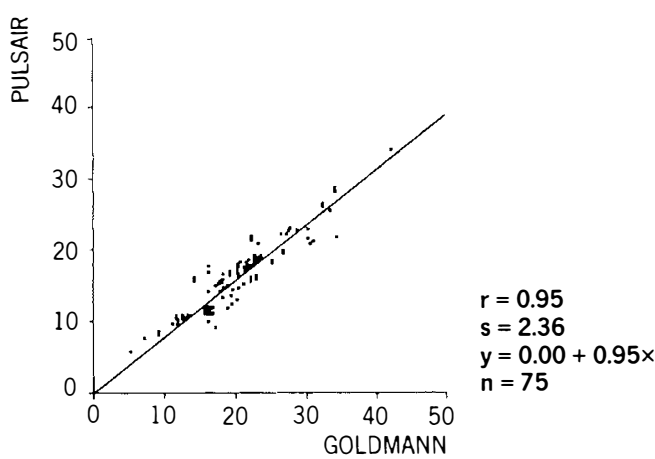

Fig. 4. Example of a scatter diagram from clinical trials after final calibration

clinics. In each case a minimum of 75 eyes were tested, and a linear regression was carried out attributing all errors to the Pulsair.

The instruments tested during 1985 and 1986, Table III, were adjusted without having access to a comprehensive calibration facility and thus the values of the slope and intercept from the regression against the Goldmann show some variation. In Table III, $\mathrm{n}$ is the number of eyes, $\mathrm{r}$ is the linear correlation coefficient, and SD is the standard deviation of the differences of the data points from the regression line.

With the development of the production calibration test facility in early 1987, the $1985 / 1986$ test instruments were used together with the results of the clinical trials; to provide a standard for calibrating subsequent instruments. The success of this calibration can be seen from the February 1987 results, shown in Table III and Fig 4.
For reference, Fig 3 shows the results of the November 1986 trial.

\section{Discussion}

Clinical trials of a new handheld air impulse Tonometer (Pulsair) have been undertaken in the United Kingdom and the United States of America on both normal and glaucomatous populations. The results have been compared against Goldmann tonometry and the statistical results calculated assuming that all errors are attributable to the Pulsair tonometer.

A high level of correlation with the Goldmann readings ( $r, 0.88$ to 0.95 ), was obtained with the Pulsair instrument with a standard deviation of differences of between 1.56 and 2.66. The results did not show any increase in the standard deviation at high pressure up to $50 \mathrm{~mm} \mathrm{Hg}$. The results shown in Fig 4 show that the calibration has been effective.

The instrument has been used by a range of people in the clinics, including ophthalmologists, optometrists, orthoptists and ophthalmic technicians. In general, all found the instrument convenient and easy to use, and patient acceptance was good - most preferring the Pulsair to the Goldmann.

There is a short learning curve to go through before it becomes easy to take a reading. However, it does not normally require more than a few minutes of practice on the glass test piece provided with the instrument to become competent to use it on a patient. Readings can then usually be obtained in a few seconds, with the total time taken for 4 readings being somewhat shorter than for Goldmann applanation tonometry.

\section{Conclusions}

The results of the trials have established the 'ease of use' accuracy, reliability and reproducibility of the Pulsair tonometer. Its portability and insensitivity to orientation means that in many cases it can be used on patients and in situations where conventional Goldmann tonometry is difficult or impossible.

\section{Addendum}

In April $1988 \mathrm{~J} \mathrm{H}$ Fisher was awarded the Duke of Edinburgh's Designers Prize, the premier award from 
the British Design Council, for the design of the Pulsair.

Grateful thanks go to Val Norris D.B.O. (D) and Fay Barnet D.B.O. (T) of Addenbrookes Hospital, Cambridge, UK, and Maria Sammartino C.O.A. and Effie Poryzees C.O.T. of Wills Eye Hospital, Philadelphia PA, U.S.A.

The authors have no commercial interest in the Pulsair Tonometer although one of us, J. H. Fisher, managed the research and development of the instrument which was contracted by Keeler Ltd to PA Technology.

\section{References}

${ }^{1}$ Grolman B: A New Tonometer System, Am J Optom and Arch Am Acad Optom, 49: 8, 64660, 1972.

${ }^{2}$ Forbes M, Pico G, Grolman B: A Non-Contact Applanation Tonometer. Arch Ophthalmol. 1974, 91: 134-40.

${ }^{3}$ Halber P, Previte L, Yellen M: 'Report on Clinical Experience with NCT'. Proceedings of the
International Glaucoma Symposium - Albi, Nov 1974.

${ }^{4}$ Decker T and Keuther C: American Optical Non-Contacting Tonometer Evaluation. Presented to Am Acad of Optom. Annual Meeting in San Francisco, Dec 1973.

${ }^{5}$ Draeger J, Jessen K, Haselmann G: Klinische und experimentelle Untersuchungen mit dem Non-Contact-Tonometer. Klin $\mathrm{Mbl}$ Augenheik. 1975, 167: 27-34.

${ }^{6}$ Dittmar P, Weinberg M, Liegl O: Erfahrungen mit dem Non-Contact-Tonometer. Klin $\mathrm{Mbl}$ Augenheilk 1975, 167: 137-41.

${ }^{7}$ Kitazawa Y, Sue T, Horie T, Deguchi T: Clinical Evaluation of a Non-Contact-Tonometer. Acta Soc Ophthalmol Jap, 1975, 79.

8 Shields MB: The Non-Contact Tonometer: Its value and limitations Surv Ophthalmol 1980, 23: 211.

${ }^{9}$ Fisher J, New Tonometer. UK Patent Application 8513108, 23 May 1985.

${ }^{10}$ Jessen K, Luebbig H, Weigelin E: Clinical and Statistical Aspects on Standardization of Tonometers. A v Graefes Arch klin exp Ophthal 1979, 209: 269-78. 